\title{
Search for Sculptor's Stone Reveals New Marble Outcrops
}

\author{
Isotope geochemistry and grain size analysis, combined with a long \\ summer's hike, start to resolve an art history puzzle. \\ By Rachel Berkowitz
}

( $\mathrm{n}$ the Greek island of Delos in the Aegean Sea, two giant marble halves of a broken torso dominate the site of an ancient sanctuary. The halves were once part of the Colossus of the Naxians, a 9-m-tall statue of the Greek god Apollo that was sculpted in the 7th century BCE and was likely the largest marble figure to have been erected on the island. Its existence was recorded by travelers in the 15th century CE, most notably by the merchant Cyriacus of Ancona, who made illustrations in 1445 that show a nearly intact statue on a marble platform. That platform remains on site, bearing a perplexing
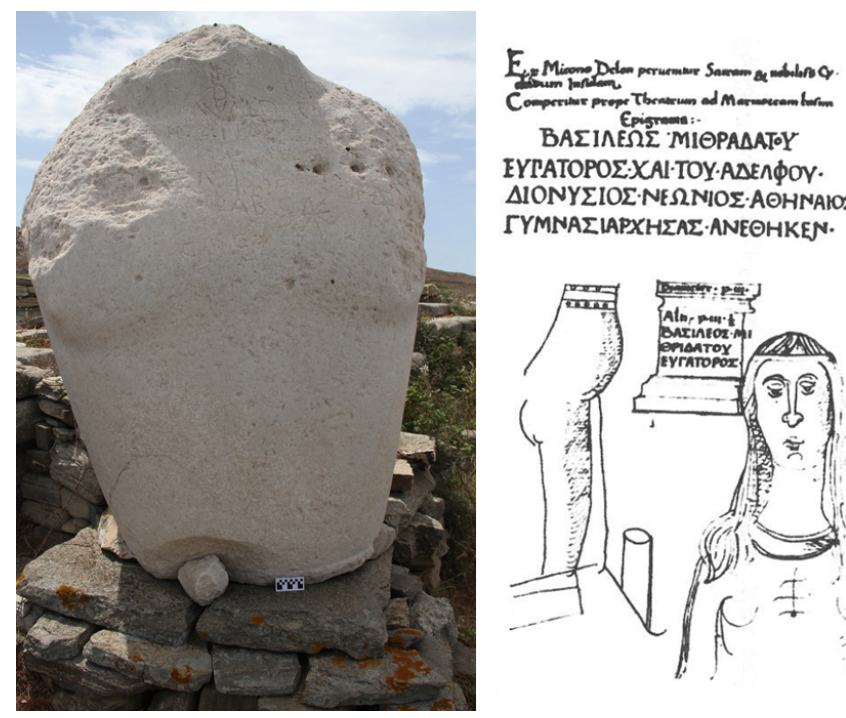

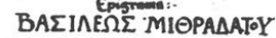
FYPATOPOE:XAI-TOY.ADEAфOY. $\triangle I O N Y \Sigma I O E \cdot N E \Omega N I O \Sigma \cdot A O H N A F E$. TYMNAELAPXHEAE·ANEOHKEN.

On the left is a portion of the upper torso of the Colossus of the Naxians, one of the largest sculptures from the Greek Bronze Age. On the right is a sketch of the statue, drawn by Cyriacus of Ancona in 1445 CE, which shows the now-missing head.

Credit: S. Pike; adapted from Archaeology 25, 3 (1972) inscription: "I am of the same stone, statue and base."

The meaning of that engraving had long puzzled art historian Kenneth Sheedy of Macquarie University in Australia. Was the enormous statue carved from a single block of marble, which must have weighed around 60 tons? Or was the statue assembled from multiple stones from the same location? Answering this riddle could give insights into the practices of ancient sculptors. Now, using geochemistry techniques, grain size analysis, and some geological intuition, Sheedy and his colleague Scott Pike, a geologist and archaeologist at Willamette University in Oregon, have traced the Apollo statue fragments to a previously unknown marble outcrop on the nearby isle of Naxos. The finding raises the prospect that ancient sculptors had a wider-than-thought network of stone sources in the region.

During the Bronze Age (3rd to 1st millennium BCE), art flourished in Greece's Cycladic archipelago, which includes Delos. Small marble figures from the early part of that period form the first coherent sculptural style known in Europe and have been found throughout the Mediterranean region. Scientists have linked the marble from which many Cycladic statues are carved to ancient quarries in the central and northern parts of the isle of Naxos. At some of those sites, larger-than-life unfinished statues from the Archaic Period (800-480 BCE) remain in situ, indicating that it may have been common practice to carve a giant like the Apollo at Delos from a single piece of stone.

In the late 1990s, when Sheedy and Pike started their quest to decipher the inscription on the Delos statue, Greece had imposed a ban on sampling marble statues for further study. 


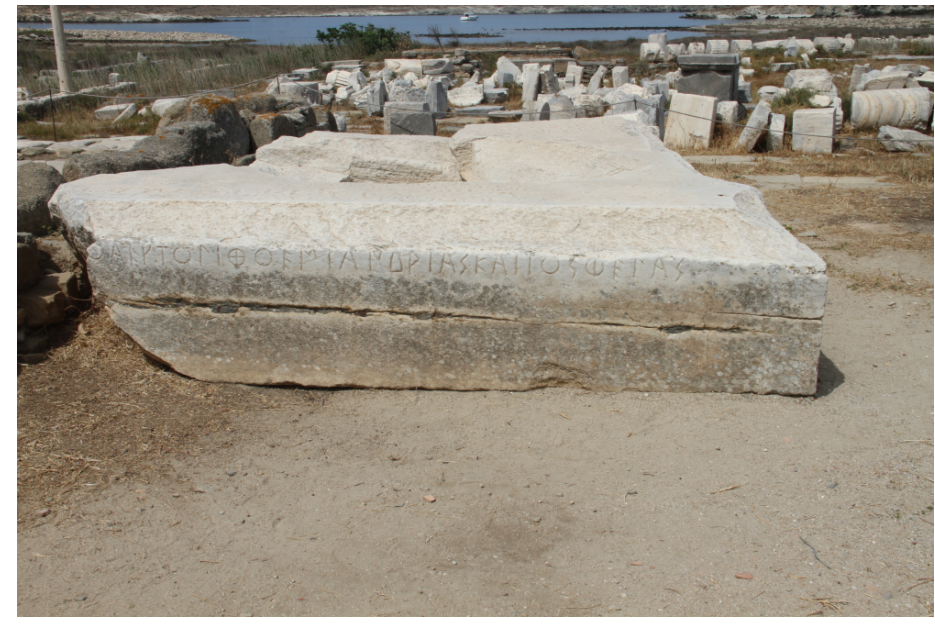

The former base of the statue is engraved with the words: "I am of the same stone, statue and base."

Credit: S. Pike/Willamette University

That ban made the Delos statue's base and torso fragments off-limits, but a broken-off foot, then on display in London's British Museum, was fair game. The researchers collected a small sample from the foot and dissolved it in acid to extract carbon dioxide. They then ran the extracted gas through a mass spectrometer to measure the isotopic ratios of carbon and oxygen. Such isotopic signature analysis is commonly used for identifying a sculpture's source stone, as the isotope ratios in marble vary from region to region according to geologic conditions during the original limestone formation and subsequent metamorphism.

The researchers compared the isotope signature in the foot sample to a database that holds isotope data on all the known archaeological marble deposits in the Aegean. From that comparison, Pike proposed that the stone originated from southeast Naxos-a region that did not host an ancient quarry, at least according to archaeological records. "If the stone came from southeast Naxos, where exactly in southeast Naxos was it?" wondered Pike.

In the summers of 2018 and 2019, Pike and his students went hunting for potential marble sources on Naxos. While trekking through the Sangri Valley, in the shadow of an Archaic era (530 $\mathrm{BCE}$ ) temple, the team spotted a small formation of marble exposed at the top of a hill, unmarked on geological maps. They took samples of these marble bands and measured isotope

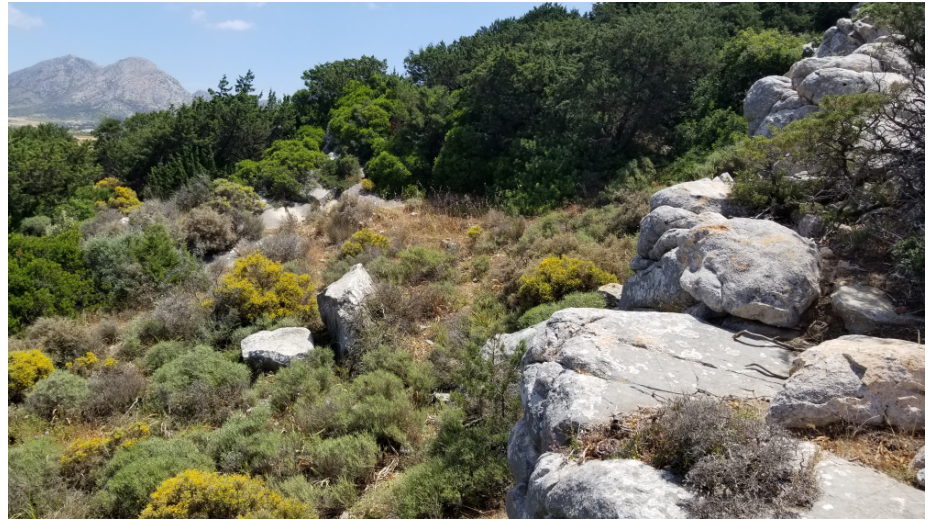

The marble from this outcropping on the Greek island of Naxos has the same isotopic signatures as fragments from the Apollo on Delos.

Credit: S. Pike/Willamette University

ratios and grain sizes. They then compared these analyses to the corresponding data on the Delos fragments, which were no longer off-limits for sample collection.

At the Annual Meeting of the Geological Society of America in Portland, Oregon, this October, Pike presented initial results that show that two of the Delos fragments share common isotope signatures with the newfound outcrops. However, one large broken piece of the statue's torso did not share the same isotope signature as the others. "The statue is not of one marble block, likely not of one marble quarry, but likely all from Naxos," says Pike. That interpretation of the mysterious engraving supports the widespread sculpting technique of carving components separately, then joining them with metal or stone attachments. It is also possible that the surviving fragments thought to be associated with one marble statue may, in fact, be from multiple statues. Analyzing the marble from other surviving fragments will fill in more details.

Having identified Naxos as the origin of the statue, the researchers now want to learn more about the marble sources in this area. This coming summer, Pike will bring a team of undergraduates to fly over the region with LiDAR and multispectral sensors to peer under the vegetation and map the outcrops. They will investigate the methods used to extract the marble and the volume of material in the area. "We can now pinpoint where other quarries might be," says Pike. 
Vancouver, Canada.

Rachel Berkowitz is a Corresponding Editor for Physics based in 